\title{
Analisis Gesture Siswa Tunarungu dalam Belajar Matematika Ditinjau dari Gender
}

\author{
Meyta Dwi Kurniasih ${ }^{1 *}$, Hinggil Darojati' ${ }^{2}$, S B Waluya ${ }^{3}, \& \operatorname{Rocmad}^{4}$ \\ 1.2. Universitas Muhammadiyah Prof DR HAMKA, ${ }^{3.4}$ Universitas Negeri Semarang
}

\section{INFO ARTICLES}

\section{Article History:}

Received: 30-04-2020

Revised: $12-05-2020$

Approved: 15-05-2020

Publish Online: 15-06-2020

\section{Key Words:}

Gesture, Deaf Students, Gender

\section{cc) (7) (2) \\ This article is licensed} under a Creative Commons AttributionShareAlike 4.0 International License.

\begin{abstract}
Body gesture is a way of expressing one's thoughts or feelings when communicating or interacting. The purpose of this study was to analyze the gestures of the deaf students in learning mathematics in terms of gender. This study was conducted in Bekasi's extraordinary State Junior High School using descriptive qualitative methods. Research instruments in the form of observation documents, interviews, and mathematical abilities test. This study shows that in learning mathematics female students issued more varied gestures than male students
\end{abstract}

\begin{abstract}
Abstrak: Gesture atau gerakan tubuh merupakan salah satu cara mengekspresikan pikiran atau perasaan seseorang ketika berkomunikasi atau berinteraksi. Tujuan penelitian ini untuk menganalisis gerak tubuh atau gerak tangan (gesture) siswa tunarungu dalam belajar matematika yang ditinjau dari gender. Penelitian dilakukan di SMP LB Negeri Bekasi dengan menggunakan metode kualitatif deskriptif. Instrumen penelitian berupa dokumen observasi, wawancara, dan tes kemampuan pemahaman matematis. Penelitian menunjukkan bahwa bahwa dalam belajar matematika siswa wanita lebih banyak mengeluarkan gesture yang variatif dibandingkan siswa laki-laki.
\end{abstract}

Correspondence Address: Jln. Limau 2 Kebayoran Baru, Jakarta Selatan, Indonesia; e-mail: meyta.dkurniasih@uhamka.ac.id

How to Cite (APA $6^{\text {th }}$ Style): Kurniasih, dkk.. (2020). Analisis Gesture Siswa Tunarungu dalam Belajar Matematika dari Gender. JKPM (Jurnal Kajian Pendidikan Matematika), Vol 5 (2): 175-182.

Copyright: Kurniasih, dkk(s), (2020)

Competing Interests Disclosures: The authors declare that they have no significant competing financial, professional or personal interests that might have influenced the performance or presentation of the work described in this manuscript. 


\section{PENDAHULUAN}

Matematika adalah alat bantu dalam memecahkan masalah dan pengembangan ilmu pengetahuan yang lainnya (Kurniasih, 2016). Membekali siswa agar dapat menggunakan matematika dan pola berpikir matematika dalam kehidupan merupakan tujuan dalam pendidikan matematika. Dengan belajar matematika, peserta didik dapat membangun pola pikir secara sistematis, logis dan konseptual. Pembelajaran matematika bukan hanya sekadar konsep yang dihapal saja, tetapi bagaimana mengajarkan siswa berpikir melalui matematika (Nurhayati \& Mariliani, 2019). Pendidikan juga merupakan kebutuhan bagi individu yang ingin maju dan pendidikan matematika bukan hanya disajikan bagi siswa normal, tetapi juga disajikan bagi siswa berkebutuhan khusus, sesuai dengan amanah pembukaan UUD 1945.

Peraturan Pemerintah Nomor 157 Tahun 2014, tentang kurikulum pendidikan khusus, menyebutkan bahwa pembelajaran peserta didik berkelainan atau berkebutuhan khusus, mengacu pada prinsip dan pendekatan pembelajaran regular yang disesuaikan belajar peserta didik, bercirikan keunikan setiap peserta didik (BNSP, 2016). Anak Berkebutuhan Khusus (ABK) meliputi kelompok tuna netra, tuna rungu, tuna wicara, tuna grahita sedang dan ringan, tuna daksa ringan dan sedang, tuna laras, HIV, AIDS, pengidap narkoba, autisme, syndrom asperger, tuna ganda, kesulitan belajar, lambat belajar, gifted dan talented serta indigo (Ginintasari, 2009:2). Salah satu yang disebut sebagai kaum berkebutuhan khusus (difabel) adalah siswa tunarungu. Siswa tunarungu adalah siswa yang kehilangan sebagian atau seluruh daya pendengarannya, sehingga mereka mengalami kesulitan dalam melakukan komunikasi. Kesulitan komunikasi tersebut sering menjadi hambatan dalam beradaptasi dan belajar. Oleh sebab itu, siswa tunarungu membutuhkan bimbingan sosial atau penanganan khusus.

Kesulitan dalam proses penyampaian informasi yang dialami siswa tunarungu, sering menjadi masalah dalam belajar di sekolah. Ini berlaku untuk seluruh pelajaran, termasuk mata pelajaran matematika karena keterbatasan dalam mendengar, maka gesture menjadi salah satu upaya yang dilakukan dalam mentransfer ilmu pengetahuan agar dapat ditangkap maksudnya oleh siswa tunarungu. Oleh sebab itu, dalam pembelajaran matematika, siswa tunarungu menggunakan gesture sebagai alat komunikasi dan berinteraksi baik terhadap guru maupun teman sebayanya. Gesture berperan sebagai fasilitator dalam menyelesaikan masalah matematis (Achadiyah et al., 2015)

Gesture pada dasarnya memiliki peran sebagai perantara antara pengguna gesture dengan pengamat karena keterbatasan yang dimiliki siswa tunarungu, maka gesture menjadi kunci inti dalam berdiskusi dan berkomunikasi. David Mc Naill membagi gesture menjadi 3 (tiga) macam yaitu Gesture ikonik, gesture metaforik dan gesture deiktik (McNeill, 2002). Gerakan pada gesture ikonik bertepatan dengan bagian dari ucapan yang dipresentasikan makna yang sama. Gesture metaforik, gesture yang menyajikan gambar dari gambar yang tidak terlihat abstraksi. Dan terakhir gesture deiktik yaitu gerakan menunjuk. Gerakan ini tidak ditunjukkan pada tempat secara fisik yang ada dimana lawan bicara sebelumnya, namun pada konsep abstrak dimana dia sebelumnya.

Analisis terhadap gesture siswa tunarungu dilakukan untuk mendapatkan informasi bagaimana mengajarkan matematika terhadap siswa tunarungu, baik laki-laki maupun wanita, sehingga mencapai hasil yang maksimal. Gesture bersifat alamiah, dan seseorang dapat mengetahui apa yang disampaikan apabila komunikasi verbal diikuti bahasa non verbal melalui bahasa tubuh. (Yoon, Thomas, \& Dreyfus, 2011). Gesture merupakan salah satu sarana efektif dalam menyampaikan pesan dalam bentuk kesan dengan cara yang tidak biasa dilakukan oleh sebuah ucapan. Penyertaan gesture dalam pembelajaran matematika, terbukti dapat mempengaruhi persepsi, pemahaman pembelajaran dan biasanya dapat mengembangkan anak (Damayanti \& Sa, 2019). Oleh sebab itu, memahami gesture siswa ketika belajar dapat mengetahui sejauh mana siswa memahami materi yang diajarkan. 
Selain kemampuan dan kematangan siswa, perbedaan gender juga memengaruhi cara belajar siswa. Perbedaan perlakuan pada laki-laki dan perempuan di rumah dan sekolah memiliki pengaruh besar terhadap identitas dan perkembangan akademik siswa (Cahyono, 2017). Pada dasarnya laki-laki dan perempuan berbeda, namun tidak boleh dibedakan perlakuannya dalam belajar, agar baik laki-laki dan perempuan memiliki kesempatan yang sama dalam menggali potensi dan bakat masing-masing. Kemampuan antara laki-laki dan perempuan sebenarnya tidak ada perbedaan yang esensial, namun perbedaan sikap yang dimiliki laki-laki dan perempuan yang menjadikan perbedaan dalam mengimplementasikan strategi-strategi belajar (Nurmaliah, 2013)

Dari uraian di atas, penelitian tentang analisis gesture siswa tunarungu dalam belajar matematika menjadi hal yang penting agar sukses dalam belajar matematika ditambah lagi jika kita tinjau dari gender, antara siswa laki-laki dan perempuan. Berdasarkan uraian di atas, maka perlu dilakukan penelitian untuk mengetahui bagaimana proses pembelajaran matematika dan tahapan berpikir siswa tuna rungu dalam memahami pembelajaran matematika jika ditinjau dari gender (jenis kelamin). Tujuan dari penelitian ini adalah menganalisis gerak tubuh atau gerak tangan (gesture) siswa tunarungu dalam belajar matematika yang ditinjau dari gender. Harapannya dapat mengukur kualitas kemampuan belajar siswa tuna rungu, sebagai indikator awal untuk mengukur kualitas proses pembelajaran matematika pada siswa tuna rungu dan sebagai referensi untuk meningkatkan kualitas pendidikan matematika khususnya pada proses pembelajaran matematika pada siswa tuna rungu.

\section{METODE}

Metode penelitian ini adalah metode deskripstif dengan pendekatan kualitatif. Tujuan penelitian ini untuk mengetahui bagaimana gesture dan deskripsinya yang dilakukan siswa tunarungu baik laki-laki maupun perempuan dalam pembelajaran matematika. Subjek penelitian ini adalah siswa-siswa tunarungu di SMPLB kelas VII tahun pelajaran 2018/2019. Teknik pengumpulan data yang dilakukan adalah dengan wawancara, lembar observasi, dokumentasi, dan tes kemampuan pemahaman matematis siswa. Berdasar pada pertimbangan penelitian untuk memilih subjek penelitian adalah siswa yang memiliki gesture dan tingkat kemampuan matematis beragam, maka diambil 4 siswa, dimana 2 siswa laki-laki (disingkat L1 dan L2) dan 2 siswa perempuan (disingkat P1 dan P2). L1 dan P1 memiliki kemampuan matematis lebih tinggi dibandingkan L2 dan P2. Hasil tes dan wawancara dari keempat siswa tersebut selanjutnya dianalisis melalui triangulasi yaitu hasil wawancara, foto, video, tes belajar matematika. Teknik analisis data dalam penelitian ini adalah reduksi data, penyajian data, dan terakhir membuat kesimpulan.

\section{HASIL PENELITIAN}

Data penelitian didapat dari tiga hal yaitu dokumen observasi, hasil wawancara, dan tes kemampuan pemahaman matematis siswa. Dari hasil observasi diketahui bahwa siswa sedang mempelajari materi bilangan. Proses pembelajaran terlihat bahwa guru harus mengulangi penjelasan, jika siswa memunculkan gesture terkesan tidak mengerti. Seperti, jika ditanyakan guru, siswa hanya menggelengkan kepala atau menunduk. Guru berusaha memberikan pemahaman kepada siswa dengan menggunakan ucapan lisan dan gesture. Seperti menepuk tangan untuk menarik perhatian siswa, dan menggunakan isyarat-isyarat jari dalam rangka menunjukkan nilai satuan pada bilangan. Kondisi di dalam kelas, siswa lebih sering duduk 
berkumpul sesama jenis (tidak saling membaur). Mereka lebih aktif dalam komunikasi secara nonverbal dengan sejenis (laki-laki dengan laki-laki dan perempuan dengan perempuan).

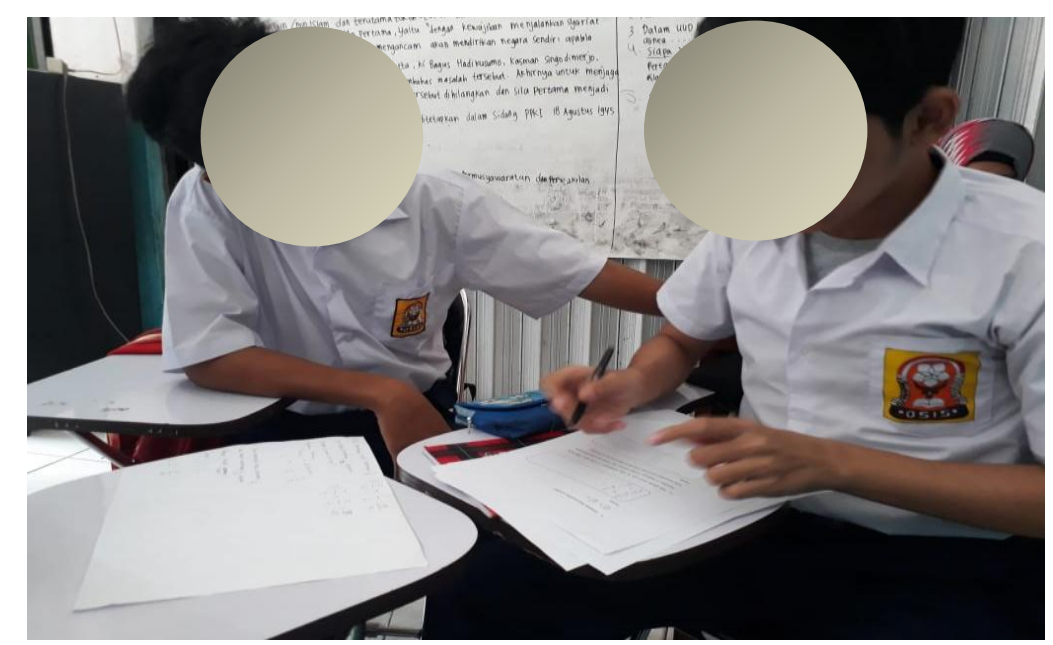

Gambar 1. L1 sedang mengerjakan dalam mengerjakan soal

Proses pembelajaran yang berlangsung, guru mulai dengan doa dan mengecek kehadiran siswa, yang kemudian dimulai dengan apersepsi tentang materi bilangan. Guru memulai pembelajaran dengan contoh soal. Contoh soal yang diberikan adalah "2,3 jika dibulatkan menjadi ...", dan beberapa soal yang lain. Siswa terlihat lebih memahami materi jika guru menggunakan angka atau simbol matematika dibandingkan dalam bentuk cerita. Hal tersebut terlihat dari gesture siswa, saat diberikan soal rutin yang berisi simbol dan angka para siswa dengan antusias mengerjakan soal tersebut. Pada Gambar 1 terlihat bahwa siswa L1 mengerjakan soal rutin yang berisi angka atau simbol matematis saja. Sedangkan P1 dan P2 mereka berkolaborasi dalam menyelesaikan soal yang diberikan. Terlihat bahwa, P2 hanya membantu P1 dalam proses perhitungan dengan meminjamkan tangannya untuk menghitung, seperti yang tampak pada Gambar 2.

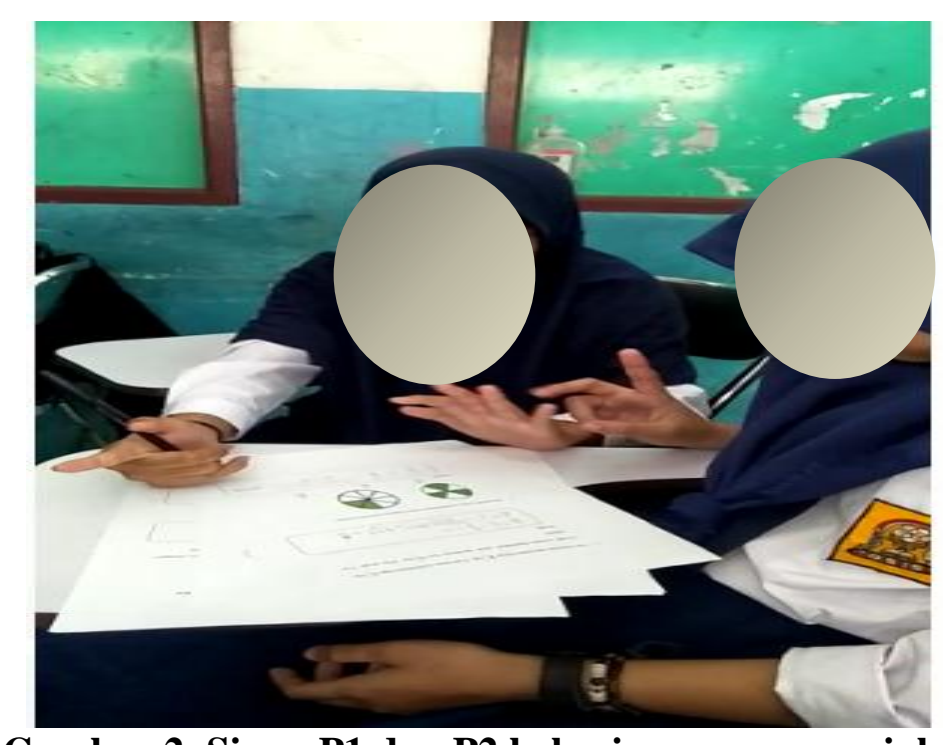

Gambar 2. Siswa P1 dan P2 bekerjasama mengerjakan soal 
Di hari yang lain, guru mengundang siswa untuk mengerjakan soal di depan kelas. Di panggil beberapa siswa untuk mengerjakan soal di depan kelas, salah satunya adalah L2. Siswa L2 saat mengerjakan soal di depan kelas, terlihat sering mengaruk-garuk kepala seperti Gambar 2. Oleh sebab itu, jika siswa mengeluarkan gesture tersebut, maka guru kembali mengulang penjelasannya.

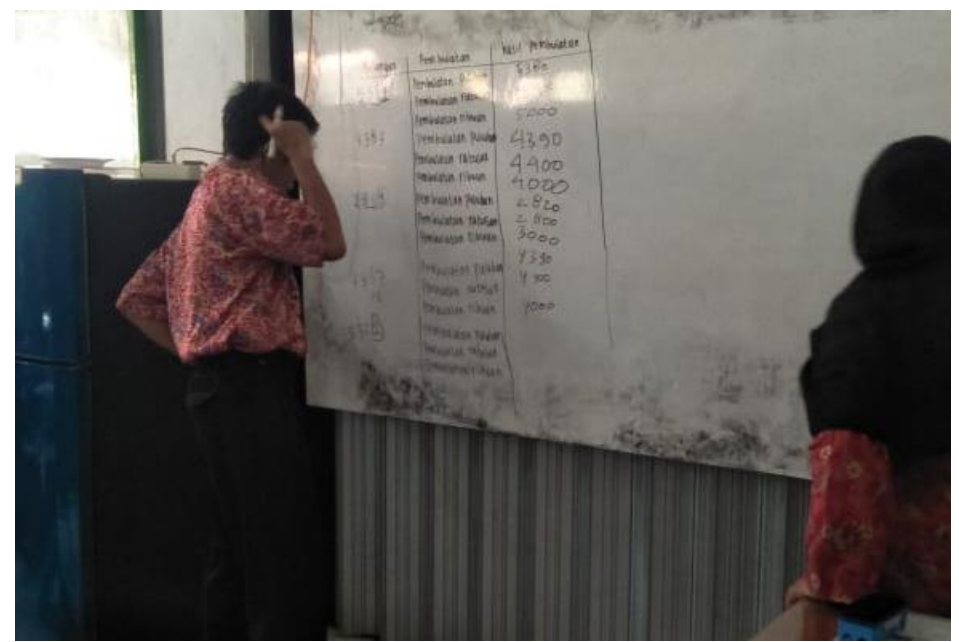

\section{Gambar 3. Siswa diminta ke depan kelas untuk menjawab soal}

Untuk mengetahui bagaimana tingkat pemahaman siswa, maka diberikan tes kemampuan pemahaman matematis dengan 3 (tiga) indikator yaitu 1) mampu menyelesaikan masalah yang berkaitan dengan operasi hitung bilangan bulat dan pecahan, 2) mampu menyelesaikan soal cerita operasi hitung pecahan hitung pecahan dengan memanfaatkan berbagai sifat opperasi hitung, dan 3) dapat membulatkan bilangan ke pembulatan puluhan, ratusan dan ribuan terdekat. Hasil dari tes kemampuan pemahaman matematis siswa tunarungu disajikan dalam Gambar 4.

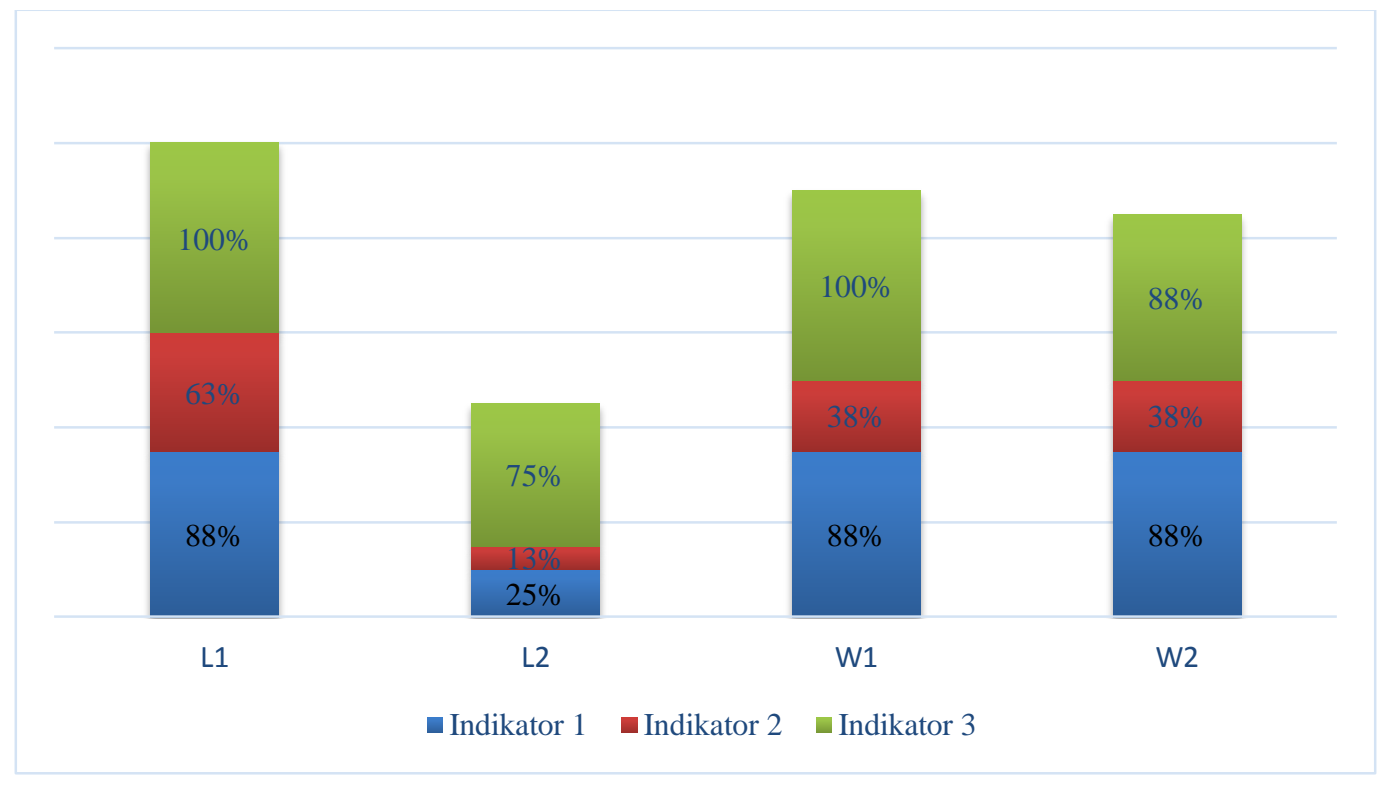

Gambar 4. Hasil tes kemampuan matematika siswa 
Dari hasil tes kemampuan pemahaman matematis siswa, diberikan 3 indikator dengan 8 soal. Hasilnya menunjukkan bahwa L1 (siswa tunarungu laki-laki 1) memiliki kemampuan matematis lebih tinggi di bandingkan keempat yang lain. Namun, jika dilihat dari indikator-indikator kemampuan pemahaman matematis tertinggi pada indikator ketiga dan paling rendah adalah untuk indikator kedua yaitu soal yang berhubungan dengan soal carita.

Dari hasil observasi di kelas, siswa L1 lebih banyak bertanya kepada guru jika ada yang tidak dia pahami. Saat dia mengalami kesulitan, ia akan menggaruk-garuk rambutnya, dan memanggil bertanya kepada guru, namun berbeda dengan L2 (siswa tunarungu laki-laki) yang saat mendapat kesulitan dalam belajar ia hanya diam (menaruh tangannya di meja, dan meletakkan kepalanya ditangannya).

\section{PEMBAHASAN}

Analisis terhadap gesture memang menjadi salah satu isu dalam pendidikan matematika, karena matematika selama ini yang dinilai sulit dan abstrak, apalagi jika dalam pembelajaran proses yang terjaadi monoton membuat siswa bosan dan menganggap matematika sebagai pelajaran yang menyeramkan dan menganggap soal-soal matematika sulit (Malasari \& Hakim, 2017). Matematika merupakan salah satu mata pelajaran penting yang harus diberikan kepada semua siswa, baik siswa normal maupun Anak Berkebutuhan Khusus (ABK). Matematika untuk siswa ABK memerlukan proses interaksi siswa dengan guru dan sumber belajar dengan berbagai model, metode dan strategi untuk mencapai tujuan pembelajaran. Anggapan tersebut bukan hanya dirasakan oleh siswa pada umumnya saja, tetapi juga oleh siswa tunarungu. Mereka yang memiliki keterbatasan dalam pendengaran, mengalami kesulitan juga saat belajar matematika. Hal tersebut terlihat dari gesture atau gerakan tubuh/tangannya. Analisis gesture siswa tunarungu dilakukan dalam rangka memahami bagaimana kondisi siswa tunarungu dalam belajar matematika.

Hasil penelitian yang dilakukan oleh empat orang subjek penelitian, yaitu dua laki-laki (L1 dan L2) dan dua siswa perempuan (P1 dan P2), dengan tingkat kemampuan yang berbeda, menunjukkan bahwa siswa L1 yang memiliki tingkat kemampuan pemahaman matematis paling tinggi, dalam belajar matematika, jika ada yang tidak dipahaminya maka ia tidak sungkan untuk bertanya. Berbeda dengan siswa yang lain, dalam bertanya mereka cenderung diam. Jika siswa menampakkan gesture lima, menggaruk-garuk kepala dan termenung (menaruh kepalanya di atas tangan), menunjukkan bahwa siswa mengalami kesulitan. Gesture dapat membawa dampak positif dalam pembelajaran seperti matematika, sains dan kosakata Bahasa asing (Cook, Friedman, Duggan, Cui, \& Popescu, 2017).

Jika dianalisis berdasar pada gender (jenis kelamin), diketahui bahwa siswa tunarungu perempuan lebih aktif dalam berdiskusi dengan kawannya yang sesama perempuan dan dalam belajar pun mereka lebih banyak menampakkan gesture yang mencirikan bahwa mereka sedang belajar matematika. Seperti saat mereka sedang melakukan operasi hitung. Berbeda dengan siswa tunarungu yang laki-laki, jika mengalami kesulitan, mereka cenderung pasif. Ini bisa dilihat dari gesture yang ditampakkan oleh L2. Dalam belajar siswa L2 hanya diam, dan memperhatikan ketika L1 sedang melakukan penyelesaian suatu soal matematika. Seperti halnya penelitian yang dilakukan oleh Whitelock dan Scanlon, bahwa wanita lebih banyak melakukan gesture dalam belajar (Whitelock \& Scanlon, 1998). Siswa P1 dan P2 banyak mengeluarkan gesture ikonik. Gesture ikonik merupakan gerakan tangan dan tubuhnya sesuai dengan yang mereka fahami (McNeill, 2002). 


\section{SIMPULAN}

Hasil penelitian ini bahwa: 1) siswa laki-laki tunarungu yang memiliki kemampuan paling tinggi, cenderung tertutup dalam belajar, 2) siswa laki-laki tunarungu yang memiliki kemampuan sedang, dalam belajar matematika lebih pada diam atau memperhatikan siswa lain mengerjakan tanpa mencoba menyelesaikan sendiri atau bertanya, 3) siswa tunarungu perempuan dengan kemampuan paling tinggi, lebih menampakkan gesture yang friendly, dia bekerjasama dengan temannya untuk menyelesaikan persoalan yang diberikan, gaya tangan/badan yang ditampilkan pun beragam seperti berhitung dengan bantuan tangan tenamnya, menggeng-gelengkan kepalanya dan sebagainya dan 4) siswa tunarungu perempuan dengan kemampuan matematis sedang, selalu menampakkan gesture aktif bergerak mencari informasi dalam menyelesaikan masalah yang diberikan.

\section{DAFTAR RUJUKAN}

Achadiyah, N. L., Abdussakir, D., Negeri Satu Atap Lesanpuro Kota Malang, S., Matematika, J., Sains dan Teknologi, F., \& Maulana Malik Ibrahim Malang, U. (2015). Penggunaan Gestur Representasional oleh Siswa dalam Memecahkan Masalah Matematis secara Kelompok. In Prosiding Seminar Nasional Sains dan Teknologi.

BNSP. Peraturan Mentri Pendidikan dan Kebudayaan Nomor 21 Tahun 2016 tantang Standar Isi Pendidikan Dasar dan Menengah., Kemendikbud § (2016).

Cahyono, B. (2017). Analisis Ketrampilan Berfikir Kritis Dalam Memecahkan Masalah Ditinjau Perbedaan Gender. Aksioma, 8(1), 50. https://doi.org/10.26877/aks.v8i1.1510

Cook, S. W., Friedman, H. S., Duggan, K. A., Cui, J., \& Popescu, V. (2017). Hand Gesture and Mathematics Learning: Lessons From an Avatar. Cognitive Science, 41(2), 518-535. https://doi.org/10.1111/cogs.12344

Damayanti, R. N., \& Sa, C. (2019). Gesture Anak Autis dalam Menyelesaikan Soal Matematika Materi Penjumlahan Bilangan Bulat. 1132-1138.

Ginintasari,R. 2009. Proses Pembelajaran Anak Berkebutuhan Khusus. Psikologi Fakultas ilmu pendidikan UPI.Bandung. Diunduh tanggal 24 maret 2016

Kurniasih, M. D. (2016). Penerapan metode inkuiri untuk kemampuan berpikir kritis matematis mahasiswa calon guru. 4(2), 751-760.

Malasari, N., \& Hakim, A. R. (2017). Pengembangan Media Belajar pada Operasi Hitung untuk Tingkat Sekolah Dasar. JKPM (Jurnal Kajian Pendidikan Matematika), 3(1), 11. https://doi.org/10.30998/jkpm.v3i1.1911

McNeill, D. (2002). Gesture and language dialectic. Acta Linguistica Hafniensia, 34(1), 7-37. https://doi.org/10.1080/03740463.2002.10414607

Nurhayati \& Marliani, N. (2019). Implementasi Model Pembelajaran Kooperatif Tipe Course Review Horay (CRH) Terhadap Kemampuan Pemecahan Masalah Matematika. JKPM (Jurnal Kajian Pendidikan Matematika), 5(1), 30.

Nurmaliah, C. (2013). Analisis keterampilan metakognisi siswa SMP Negeri di kota malang berdasarkan kemampuan awal, tingkat kelas, dan jenis kelain. Jurnal Biologi Edukasi, 1(2), 18- 21.

Whitelock, D., \& Scanlon, E. (1998). The roles of gaze, gesture and gender in CSCL. Journal of Computer 
182 Kurniasih, dkk

Assisted Learning, Vol. 14, pp. 158-165. https://doi.org/10.1046/j.1365-2729.1998.1420158.x

Yoon, C., Thomas, M. O. J., \& Dreyfus, T. (2011). Grounded blends and mathematical gesture spaces: Developing mathematical understandings via gestures. Educational Studies in Mathematics, 78(3), 371-393. https://doi.org/10.1007/s10649-011-9329-y 